\title{
Fidel Castro Ruz: presencia y perdurabilidad en Sancti Spiritus
}

\author{
Fidel Castro Ruz: presence and endurance \\ in Sancti Spiritus
}

\author{
Yaney Rodríguez Muñoz* \\ Hanoi Guillot Pérez***
}

\begin{abstract}
* Profesora en la Universidad de Sancti Spiritus José Martí Pérez, Cuba. Es Máster en Historia y Cultura en Cuba por el Instituto Superior Pedagógico José de la Luz y Caballero, de Holguín y actualmente cursa un Doctorado en Ciencias de la Educación, en la Universidad de Sancti Spiritus. Es Profesora Auxiliar del Departamento de Historia y Marxismo Leninismo, de la UNISS. Entre sus publicaciones recientes se encuentran el capítulo "La Caravana de la Libertad, tránsito por Sancti Spiritus" en Fidel Castro: Caravana de la Libertad y perdurabilidad de su legado (2020). Sus investigaciones forman parte del proyecto de investigación Institucional del Departamento de Historia y Marxismo Leninismo de la UNISS titulado "Historia, pensamiento e innovación educativa". Correo electrónico: yaney@uniss.edu.cu

(D) https://orcid.org/oooo-oooI-5888-3975
\end{abstract}

** Profesora en la Universidad de Sancti Spiritus José Martí Pérez, Cuba. Es Máster en Ciencias Pedagógicas por el Instituto Superior Pedagógico Capitán Silverio Blanco Núñez, de Sancti Spiritus y Profesora Auxiliar del Departamento de Historia y Marxismo Leninismo, de la UNISS. Entre sus publicaciones recientes se encuentran "Necesidad, posibilidad y realidad de la enseñanza de la enseñanza de la obra martiana" en Revista Pedagogía y Sociedad (2019) y "Panorama histórico de la educación musical en Cuba y Sancti Spiritus" en Revista Pedagogía y Sociedad. Sus investigaciones forman parte del proyecto de investigación institucional del Departamento de Historia y Marxismo Leninismo de la UNISS titulado "Historia, pensamiento e innovación educativa". Correo electrónico: hgperez@uniss.edu.cu

(i) https://orcid.org/0000-0002-2443-072I

Historial editorial

Recibido: 24-abril-2019

Aceptado: 15-noviembre-2020

Publicado: 29-enero-2021

ISSN-e: 2594-2956 
Fidel Castro Ruz: presencia y perdurabilidad en Sancti Spiritus

\section{Resumen}

En este ensayo se realiza un análisis de la presencia de Fidel Castro Ruz en Sancti Spiritus, provincia situada en el centro de la Isla de Cuba, su llegada junto a los rebeldes, en la caravana de la victoria, el 6 de enero de 1959, a la ciudad y el recibimiento que el pueblo espirituano le hace. Además, se presentan las ideas esenciales de su discurso, ese día, desde el balcón de la antigua Sociedad El progreso, hoy biblioteca provincial Rubén Martínez Villena; también se expone el impacto y las experiencias de los participantes en ese acto. Del mismo modo, se muestra el retorno de Fidel a la ciudad, para hacer frente a la conspiración trujillista en el Escambray, en agosto de 1959, y para verificar las obras de la Revolución en el territorio, sobre todo aquellas que le dan cumplimento a las promesas hechas en el conocido Programa de la Revolución o programa del Moncada "La Historia me Absolverá". Igualmente se presenta el tributo que el pueblo espirituano le rindiera al invicto comandante a partir de su fallecimiento, el 25 de noviembre de 20I6, así como el homenaje durante "la

186 caravana al reverso", o sea el paso de sus cenizas rumbo a Santiago de Cuba, por la provincia espirituana.

Palabras Clave: Caravana de la victoria, programa de la Revolución, impacto, tributo.
Fidel Castro Ruz: presence and endurance in Sancti Spiritus

\section{Abstract}

In this essay, it is analyzed the presence of Fidel Castro Ruz in Sancti Spiritus, a province located in the center of the Island of Cuba. It is also analyzed his arrival with the rebels, in the caravan of victory on January 6 I959 to the city and the reception made by the sancti spiritus' people. Moreover the essential ideas of his speech that day from the balcony of the old Progress Society, of what is today Ruben Martínez Villena provincial library are presented. In addition, some of the impacts and experiences of the participants in that act are discussed. Similarly, Fidel's return to the city to deal with the Trujillista conspiracy in the Escambray in August 1959 and to check the works of the Revolution in the territory, especially those that comply with the promises made in the well-known Revolution Program or Moncada program "History Will Absolve Me", are described. Likewise, it is presented the tribute that the sancti spiritus people paid to the undefeated commander to his death on November 25, 2016, as well as the tribute during "the caravan on the reverse", that is, the passage of his ashes to Santiago of Cuba through the sancti spiritus province.

Keywords: Victory caravan, Revolution program, impact, tribute. 
Fidel Castro Ruz: présence et durabilité à Sancti Spiritus

\section{Résumé}

Cet essai analyse la présence de Fidel Castro Ruz à Sancti Spiritus, province située au centre de l'île de Cuba, son arrivée aux côtés des rebelles, dans la caravane de la victoire, le 6 janvier I959, la ville et l'accueil que le peuple spirituel lui fait. En outre, les idées essentielles de son discours, ce jour-là, sont présentées depuis le balcon de l'ancienne Société Le Progrès, aujourd'hui bibliothèque provinciale Rubén Martinez Villena ; sont également exposés quelques-uns des impacts et des expériences des participants à cet événement. De même, il montre le retour de Fidel dans la ville, pour faire face à la conspiration trujilliste sur l'Escambray, en août 1959, et pour vérifier les travaux de la Révolution sur le territoire, surtout celles qui donnent effet aux promesses faites dans le fameux Programme de la Révolution ou programme du Moncada "L'Histoire m'absoudra". Il y a également le tribut que le peuple spirituel a rendu à l'invaincu commandant à partir de son décès, le 25 novembre 2016, ainsi que l'hommage pendant ou "la caravane au dos", c'est-à-dire le passage de ses cendres vers Santiago de Cuba, par la province spiritueuse.

Mots-clés: Caravane de la victoire, programme de la Révolution, impact, hommage.
Fidel Castro Ruz: obecnosc i wplyw w Sancti Spiritus

\section{Streszczenie}

Esej analizuje obecnośc Fidela Castro Ruza w Sancti Spiritus, prowincji położonej w centrum Wyspy Kuby, jego przybyciu z rebeliantami, w karawanie zwycięstwa, 6 stycznia 1959 roku, do miasta i powitania przez mieszkancow miasta. Prezentowane sa , podstawowe idee jego przemowymowy, $\mathrm{z}$ balkonu domu nalezacego do Zjednoczenia Progress, dziś biblioteki prowincjonalnej Rubén Martínez Villena; przrezentuje sie takze doświadczenia uczestników tego wydarzenia. Przedstawiony jest tez powrot Fidela do miasta, aby stawić czoła konspiracji Trujillista w Escambray, w sierpniu 1959 roku, i zweryfikować wplyw rewolucji na terytorium, zwłaszcza obietnice zawarte $\mathrm{w}$ programie rewolucji lub planie Moncada "Historia mnie rozgrzeje". Przedstawiono również hołd, jaki mieszkancy oddali dowódcy po jego śmierci 25 listopada 2016 r., a także hołd podczas karawana $\mathrm{z}$ prochami, ktora przybyla do Santiago de Cuba.

Slowa kluczowe: Karawana zwyciestwa, program rewolucji, wpływ, hołd 


\section{Introducción}

Desde el presente ensayo se realiza un homenaje al líder de la Revolución cubana y a su labor a favor de la libertad y la independencia, a partir del rescate de fuentes primarias del conocimiento histórico; entre las que se incluyen fuentes orales en las que se exponen las vivencias de quienes, junto a él, protagonizaron las principales acciones que imponía la época.

Los años cincuenta del pasado siglo estuvieron cargados de sueños; una nueva generación de revolucionarios, guiada por un hombre de ideas avanzadas y con una visión del deber ser casi nunca antes vista, se encargaría de darle un giro a la historia.

Fidel siempre estuvo consciente del inmenso desafío que tenía por delante; pero lo emprendió con valentía, decisión y todo el optimismo del mundo. En esos días de enero de 1959 su fe en la victoria era confirmada por los hechos. La Caravana de la Libertad recorrió la Isla de pueblo en pueblo, de Oriente a Occidente y los jóvenes barbudos, con su líder al frente, le dieron a Cuba la tan ansiada esperanza.

Fidel multiplicó el tiempo para hablar en cada ciudad donde tuvo la oportunidad, para departir con los cubanos que lo vitoreaban en su paso hacia la capital. Y en ese camino triunfal, llegó a la tierra del Yayabo, Sancti Spíritus -cuna de hombres como Honorato del Castillo Cancio y Serafín Sánchez Valdivia- el 6 de enero de 1959.

El lunes 5 de enero, los barbudos entraron a las tierras de la actual provincia de Sancti Spíritus, la cuarta villa fundada en el país. El primer

188 poblado que los recibió fue Jatibonico, donde una multitud, situada sobre el paso superior del ferrocarril, aplaudía y aclamaba.

El impacto del recorrido por el pueblo espirituano fue recogido en palabras escritas del Comandante de la Revolución, Juan Almeida Bosque, tiempo después, quien relató al respecto: 
[...] El pueblo desbordado de alegría nos recibe a ambos lados de la carretera que atraviesa este poblado [...] Después de recorrer un largo tramo, ya oscuro, las luces de los carros nos permiten ver la mole de hierro del puente sobre el río Zaza. Tarde en la noche de este lunes 5 de enero, arribamos a la ciudad de Sancti Spíritus. Llegamos al parque Serafín Sánchez Valdivia. A pesar de la lluvia y el frío, otra vez se hace patente la admiración, el cariño y la alegría del pueblo. Pasada la medianoche, desde los balcones de la Sociedad El Progreso, Fidel le habla (2002, p. 360).

Como regalo de Reyes, fue aquella entrada triunfal a Sancti Spiritus de la caravana de barbudos, guerreros con aroma de manigua, pelos largos y collares de semillas, aquel martes 6 de enero, con Fidel al frente. Desde horas tempranas de la noche, los habitantes se congregaron en el parque Serafín Sánchez Valdivia para esperar al líder de la Revolución, quien llegó aproximadamente a la una de la madrugada. Era una noche fría y de lloviznas; sin embargo, eso no amedrentó a la gente sencilla que esperaba a su comandante. Ese día es recordado con especial emoción por todos aquellos que lo vivieron.

Para José Ramón Polanco, quien en aquel momento contaba apenas con 15 años de edad y era estudiante de la especialidad de Mecánica, en la Escuela de Artes y Oficios, la vida de pronto había dado un enorme vuelco. Fue protagonista de aquel suceso que cambiaría el rumbo en la vida de los espirituanos y como joven de aquella generación que se inicia con la Revolución, tuvo una percepción optimista de esos hombres que cumplieron la promesa martiana de una sociedad con todos y para el bien de todos.

[...] Como a la una y treinta de la madrugada [...] se bajó Fidel de un blindado y lo subieron hacia el edificio de la Sociedad El Progreso hoy Biblioteca Provincial Rubén Martínez Villena-mientras todo el mundo gritaba: “FFidel!, ¡Fidel!”, y de la multitud enardecida salía un clamor tremendo [...] Yo me mantuve abajo. La gente pedía a gritos que Fidel hablara y, al poco rato, él se asomó a un balcón del edificio 
y habló. Pronunció un discurso muy emotivo, memorable (J.R. Polanco, comunicación personal, 2013).

Luis Morales Pina, Moralito, jefe de Acción y Sabotaje del Directorio Revolucionario I3 de marzo, y presidente de la Federación de Estudiantes de la Segunda Enseñanza en Sancti Spíritus, afirma que su vida tuvo un antes y un después en aquellos días finales de diciembre de 1958 e inicios de enero de I959, cuando los acontecimientos se sucedían a un ritmo acelerado y cada suceso tenía un efecto trascendente. $Y$ añadió:

Llegó un momento en que Fidel, rodeado de gente mayor, preguntó dónde estaban los estudiantes, y entonces alguien miró en derredor y dijo: "Mire, allí", señaló para mí y me llamaron. Yo me acerqué y cuando estuve a su lado lo primero que hizo fue ponerme una mano en el hombro y expresó: "Dicen que sin azúcar no hay país — que era un eslogan famoso en la Cuba de aquellos tiempos-, pero de ahora en adelante, con azúcar o sin azúcar, tiene que haber país y si no tenemos frijoles tendremos malanga, y si no tenemos malanga, tendremos calabaza, y si no tenemos calabaza, tendremos yuca..." Aquellos fueron momentos inolvidables, de esos que solo se viven una vez en la vida y no todos tienen un privilegio de esa dimensión. Para mí constituye un don del destino que 54 años después podamos estar evocando esa proeza con la Revolución en el poder y sus promesas cumplidas (L. Morales Piña, comunicación personal, 2013).

Así muestra Fidel, desde los inicios de la propia Revolución triunfante, la confianza que tiene en los jóvenes y su firme convicción que ellos, los estudiantes y jóvenes, son la cantera fundamental de la nueva sociedad; idea que siempre dejó bien clara en cada una de sus intervenciones y tareas esenciales del proceso revolucionario.

Ya sobre las dos de la madrugada, en medio de la algarabía y aplausos, el héroe cubano, Fidel, comenzó su alocución. Inició su discurso con una frase que conquistó el corazón de la multitud: "No podía ser para 
mí, esta ciudad de Sancti Spíritus, una ciudad más en nuestro recorrido” (Castro, I959, párr. I). Y añadió:

Si las ciudades valen por lo que valen sus hijos, si las ciudades valen por lo que se han sacrificado en bien de la patria, si las ciudades valen por el espíritu y la moral de sus habitantes, por el fervor de sus hijos, por la fe y el entusiasmo con que defienden una idea, Sancti Spíritus no podía ser una ciudad más. Y si las ciudades se admiran y los pueblos se quieren por lo que han tenido de fe en las horas difíciles, es lógico que hacia esta ciudad, como hacia otras, especialmente en nuestra patria, sintamos nosotros especial cariño (Castro, 1959, párr. 2).

Con esas palabras levanta el ánimo de los espirituanos al exaltar el papel de este pueblo en las diferentes etapas de la lucha por la independencia nacional.

El veterano del Ejército Rebelde Alcibíades Aguiar, quien formó parte de aquella marcha triunfal, recordó cuando Fidel reconoció la valentía de esta localidad, al expresar que fueron muchos los oficiales de la región que se habían distinguido en la lucha contra Fulgencio Batista.

Fidel aclara que a partir de ese momento se le darían al pueblo todas las posibilidades para que ellos mismos hagan su propia historia, basados en las enseñanzas de las etapas anteriores y evitando volver a caer en manos enemigas que esclavicen y le ultrajen lo que tanto esfuerzo ha costado, además señala el verdadero significado de la Revolución para Cuba y sus hombres:

[...] es que el pueblo comprende que por primera vez, desde la llegada de Cristóbal Colón, hace 400 años aproximadamente, ipor primera vez va a haber una revolución en Cuba". Y precisó: "Esta vez - y eso es lo que comprende el pueblo al cabo de cuatro siglos-, por primera vez un pueblo manda; por primera vez los hombres que tienen las armas en la mano se inclinan reverentes ante el pueblo de Cuba". En sus palabras el jefe de la Revolución alertó: "Es bueno que los pueblos no olviden, para que no vuelva nadie más a escribir: Cuba, país de poca memoria. Lo que vamos a escribir la próxima vez es: Cuba, país de 
mucha memoria [...] El triunfo de esta Revolución es una reparación moral, no solo para los que han caído en esta lucha. Pienso con satisfacción que el triunfo de esta Revolución será la realización no solo de los sueños de los hombres de nuestra generación, sino también de los sueños de la generación que se sacrificó en la lucha contra la tiranía de Machado y la realización de los sueños de nuestros libertadores que no están realizados todavía (Castro, 1959, párr. 9 y 82).

El Comandante alertó acerca de lo difícil que podría ser cada etapa de la Revolución, la importancia de la unidad, el apoyo de todos a cada tarea del proceso y, también, sobre la labor que el enemigo realizaría para obstaculizar el camino trazado por el pueblo y su gobierno; pero enfatiza que él confía en la capacidad que tienen los cubanos para luchar por mantener los logros alcanzados y los que vendrán de ahora en adelante:

[...] el pueblo no se puede dormir sobre los laureles; que el camino que tenemos por delante es un camino largo y duro; que la Revolución en su etapa constructiva no será un paseo; [...]; que toda obra justa encontrará resistencia; que el enemigo agazapado, [...] tratará de poner en nuestro camino todos los obstáculos, se asociará con cuantos enemigos de Cuba pueda encontrar y estaremos en la obligación de mantenernos siempre alertas, siempre en guardia; [...]; que agotará todos los medios por sembrar la muerte entre los dirigentes de la Revolución, lo que no será en definitiva, tan difícil, porque nosotros nunca nos sustraeremos al contacto del pueblo [...] Todos los peligros que una revolución tiene en su camino los tendremos que afrontar, tal vez amenazas extranjeras, tal vez agresiones extranjeras; pero frente a todo ello, hay, sin embargo, una inconmovible fe; la fe que nace de dos cosas: de la confianza que tenemos en nosotros mismos y de la confianza que tenemos en nuestro pueblo (Castro, I959, párr. 62 y 66).

Una de las características de nuestro proceso es que en todo momento ha sido marcado por una profunda democracia y ese ha sido el pensamiento perenne de Fidel Castro, desde que se inició en la lucha 
por la independencia y esas ideas se las trasmitió a los espirituanos aquella madrugada fría, pero llena de calor y fervor revolucionario:

[...] Yo creo que los hombres públicos deben estar en consulta permanente con su pueblo [...]Para saber lo que el pueblo quiere, no hay más que venir a hablar con el pueblo, y esa será siempre nuestra línea de conducta; y el día en que yo no pueda pararme delante del pueblo, el día en que no pueda discutir con el pueblo, ese día para mí habrá terminado toda misión y toda función de carácter público [...] El gobernante que fuese capaz solamente de saber escuchar al pueblo, sería un formidable gobernante... (Castro, 1959, párr. 74, 77 y I00).

Así lo hizo, pues se inician en Cuba una serie de consultas populares, ante cada medida tomada por la Revolución y era el pueblo quien decidía su cumplimiento. Así se hizo la Ley de Reforma Agraria, las nacionalizaciones de las empresas nacionales y extranjeras, la campaña de alfabetización, las campañas de salud, la defensa en Girón. Estas consultas populares se convirtieron en una tradición en Cuba.

Fidel en sus palabras expuso que lo prometido en el Programa del Moncada se haría realidad, pero las primeras medidas que se tomarían, iniciarían en la Sierra Maestra en homenaje a que allí se inició la Revolución y entonces se trasladarían a todo el país. Con ellas se lograría formar un nuevo cubano culto y virtuoso; de esa manera impulsó una serie de medidas en el sector de la educación, dentro de las que se destacan los destacamentos de maestros voluntarios y la campaña de alfabetización:

A lo primero que voy a tener el gusto de dedicar mi esfuerzo, junto con otras muchas cosas, es a hacer la primera ciudad escolar, con el propósito de que pueda albergar y educar, dentro de los más modernos sistemas de la pedagogía, [...] 20 ooo niñas y niños... (Castro, 1959, párr. 90).

La idea de independencia total la ratificó cuando expresó: “Aquí no tenemos que pedirle permiso a nadie para hacer nada, aquí vamos a 
hacer lo que le convenga a Cuba en todas las circunstancias, y nuestro derecho sabremos defenderlo... (Castro, 1959, párr. I06).

La reafirmación del grito mambí - qque viva Cuba libre!-, con que Fidel concluyó su discurso, le daba continuidad a la obra revolucionaria y fue acogido por centenares de hombres y mujeres que, a pesar de la llovizna y el frío, vivieron aquel momento inolvidable de tener, por primera vez, a Fidel en su tierra.

De la ciudad de Sancti Spíritus partió la Caravana rumbo a Santa Clara ese 6 de enero. En su recorrido se tuvo que desviarse unos quince kilómetros del eje longitudinal de la Carretera Central y cruzar por el batey del entonces central de los Rionda, como consecuencia de que el 2I de diciembre pasado, comandos revolucionarios habían derribado el puente de La Trinchera, en la vía central, sobre el río Tuinucú, durante las acciones realizadas para la toma de Guayos y Cabaiguán, lo cual había dejado incomunicado Sancti Spíritus de esos pueblos y de Santa Clara. Sin embargo, esto no impidió que los barbudos pasaran llenos de sueños por Guayos y Cabaiguán, tierra de tabaco cultivado en su mayoría por isleños (de Canarias).

La entrada de la Caravana en Sancti Spíritus fue un sueño hecho realidad. Era la primera vez que el líder de la Revolución visitaba tierras espirituanas y ello marcó el inicio de las grandes transformaciones en la región, reafirmó la confianza del pueblo en aquellos jóvenes que con una ilusión llevaron la luz de la libertad a toda la Isla y estableció un compromiso de ambas partes con el propósito de hacer realidad la promesa del Moncada.

194 El Gobierno Revolucionario, con Fidel desde el cargo de primer ministro, asumido el I6 de febrero, inició el cumplimiento de las promesas expuestas en el Programa del Moncada, revelado en su alegato de autodefensa, conocido como La Historia me Absolverá. 
Como parte de las acciones que se acometieron para comprobar la marcha de las transformaciones en diferentes lugares del país, el Comandante en Jefe inició un recorrido por varias regiones y volvió a tierras espirituanas; de esa manera cumplió lo que había expresado en su discurso aquel 6 de enero de I959: "No será esta la única reunión, aquí volveremos. [...]" (Castro, I959, párr. 84).

Así lo hizo y el I2 de agosto de 1959, el líder de la Revolución Cubana llegó a Trinidad, acompañado de Camilo, Celia y otros oficiales del Ejército Rebelde, para echar por tierra el intento del dictador dominicano Rafael Leónidas Trujillo, de derrocar la Revolución. Ese 13 de agosto, Fidel cumplió sus 33 años de edad en tierras espirituanas. Aquel día señaló que la victoria sobre el trujillismo era una importante victoria revolucionaria y una señal de los tiempos que vendrían (Castro, 1959).

Ante el empuje de la Revolución y el desarrollo de las obras de beneficio social, así como las perspectivas de un avance propio, el II de diciembre de 1959, los periódicos reseñaron su primera visita a la zona de Jatibonico, al poblado de Cristales en el centro del país, donde existían posibilidades para la industria petrolera. Allí conversó con obreros y directivos, saludó a los lugareños, preguntó, sugirió, se preocupó por las condiciones de labor de los trabajadores y prometió que el Gobierno iba a aportar los recursos para desarrollar una investigación geológica que permitiera definir las potencialidades de aquel territorio. Ese contacto directo de Fidel con los trabajadores, con su pueblo, fue lo que lo caracterizó durante toda su vida como líder revolucionario.

Los años 1960-196i fueron testigos de la presencia de Fidel en estas tierras durante la Lucha contra Bandidos, sobre todo en la llamada Limpia del Escambray, que lo llevó a que, a finales de 1960, se presentara en el cuartel de Cabaiguán para coordinar acciones contra una banda que operaba en la zona de Manaquitas, allí después de las acciones, constituyó la granja del pueblo Noel Sancho Valladares. 
Las medidas de la Revolución provocaron la reacción de grupos opositores, que actuaron contra los campesinos y los maestros voluntarios que cumplían con el deber de llevar la luz de la enseñanza a los campos cubanos, consecuencia de ello fue el asesinato del maestro voluntario Conrado Benítez. Al conocer el hecho, el líder de la Revolución se dirigió al lugar y se incorporó a las acciones contra la banda de Osvaldo Ramírez García, responsable de ese crimen.

El Escambray fue centro de constantes visitas del Comandante para analizar aspectos medulares de la región, tales como la producción lechera, ganadera y forestal, el estado de los caminos y el desarrollo del plan del río Agabama, sitio donde vio la posibilidad de construir una hidroeléctrica con vistas al regadío en la zona de Fomento y Trinidad, para impulsar el cultivo de caña, tabaco y pastos.

También se preocupó por la educación; en esta dirección, cabe destacar la visita del i8 de julio de 1966 a la escuela formadora de maestros Makarenko, donde realizó una intervención ante los maestros y estudiantes; en sus palabras se evidenció un gran optimismo y confianza en la formación de los maestros cubanos, de los nuevos maestros, al respecto declaró:

[...] Necesitamos formar un tipo de maestros capaces de ir a enseñar no solo en el pico Turquino, sino maestros capaces de estar dispuestos a enseñar en cualquier parte del mundo donde un pueblo hermano los necesitase. Y es este el tipo de maestros que queremos formar, que aspiramos a formar y que creemos que estamos formando (Castro, 1966, párr. 4I).

Y basados en ese principio, se fortaleció la formación de maestros en el país, quienes han cumplido importantes misiones en Cuba y el mundo, y se han convertido en el arma ideológica fundamental de la Revolución.

En esta zona también analizó las posibilidades del desarrollo del turismo, en la propia zona del Escambray, a partir de la construcción de 
un hotel en la zona de Ancón, playa que debería convertirse en nuestro Varadero del sur. Otras urgencias a resolver en esa zona eran los problemas del transporte y la salud, y Fidel prometió encontrar las soluciones.

Ante el desarrollo de la agricultura en Cuba y la política de la inserción femenina al trabajo y a todas las obras de la Revolución, se organizó en el territorio el conocido Plan Banao, proyecto agrícola con novedosa tecnología y alta productividad, en el cual Fidel se involucró, pues se preocupaba por la productividad y el papel que jugaba la mujer; así, el

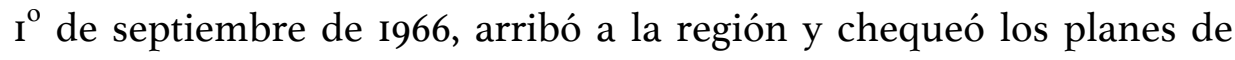
producción de fresas, cítricos y cebolla, así como la incorporación femenina al trabajo.

Yaguajay es el sitio donde la presencia de Camilo se eternizó; allí, en el fragor de la lucha insurreccional, les prometió a los habitantes de Meneses una escuela. Fidel visitó ese poblado, los pobladores le recordaron la promesa de Camilo, a lo que Comandante respondió: “[...] si es una promesa de Camilo hay que cumplirla y si les parece bien yo vendré a inaugurarla..." (Abreu, Aneiros y Fontaine, 20I8, p. 20).

El I5 de septiembre de i97I, el líder de la Revolución dejó inaugurado el seminternado de primaria Héroe de Yaguajay. Ese día, en su discurso expuso algunas de sus ideas esenciales relacionadas con la educación de las nuevas generaciones y la forma en la que se debía realizar; resaltó una vez más la necesidad del vínculo del estudio con el trabajo:

[...] Queremos que nuestra educación sea cada vez superior [...] ¿y qué podemos concebir nosotros como una educación superior? ¿Qué tipo de jóvenes quieren ustedes que se eduquen aquí? ¿Qué tipo de nueva generación? Una generación bien educada, de trabajadores. Y educar es educar para el futuro, educar para vivir en esa sociedad comunista... (Castro, 1971, párr. I3-I4). 
Una vez más Fidel señala a la educación como la vía esencial para forjar la nueva sociedad a la que se aspiraba, está ahí la cantera de la salvaguarda de la Revolución.

Las cortinas de las presas Legibre y Zaza habían tenido varias dificultades ante las intensas lluvias; por ello, el I2 de junio de 1969, Fidel llegó a Santi Spíritus, para evaluar el peligro que significaba una posible rotura de la cortina de la primera, en esos momentos en construcción.

Esta preocupación fue constante y se evidenció también en octubre de I999, ante las precipitaciones asociadas con el huracán Irene, el llenado de la segunda e inundaciones en los poblados de Tunas de Zaza y El Médano. Por primera vez en Cuba, se orientó que se destinara el hotel Zaza a la atención de los damnificados, sobre todo, de embarazadas y madres con niños pequeños.

La producción cañera es la esencia agrícola de la provincia; de ello se preocupó Fidel en persona. Entre el 28 de febrero y el 2 de marzo de I97I, estudió el proyecto del pueblo cañero en la zona del central FNTA, en Trinidad también chequeó la posible construcción de la presa y la hidroeléctrica sobre el río Agabama, así como la necesidad de construir y reparar los viales en los poblados de la zona.

El crecimiento económico de la provincia era muy importante para sus pobladores y para el país; constituía una urgencia desarrollar la producción de materiales de la construcción en Cuba. Por ello, al detectarse los yacimientos de materias primas en el poblado de Siguaney, se decidió la construcción de una fábrica de cemento en ese lugar; así, el I6 y 17 de septiembre de 197I, Fidel evaluó con Faustino

198 Pérez la marcha de la construcción de la referida fábrica y también de la presa Zaza; además, visitó la vaquería Primera del Yayabo y el combinado de productos alimenticios Río Zaza.

El 26 de julio de I986, con motivo de las conmemoraciones por aquella fecha gloriosa, Fidel les habló a los espirituanos en la Plaza de Los 
Olivos; en su discurso exaltó los logros de la provincia en la agricultura, la industria, la producción azucarera, el ferrocarril, el turismo, la cultura, la construcción, el deporte y la educación. Al respecto, llamó a dar un salto en la calidad de la enseñanza y declaró: “[...] Es una necesidad del desarrollo y una necesidad del futuro del país que exijamos cada vez más en la educación" (Castro, I986, párr. 98).

Asimismo, alertó sobre la importancia de la lucha contra las tendencias negativas que ya se presentaban en la vida socioeconómica de la nación y planteó al respecto:

Tenemos que hacernos el propósito firme de superar todas esas tendencias negativas y hacer un esfuerzo, dar un salto de calidad en la Revolución, entonces verán cuántas más cosas hacemos y podemos hacer, y mejor hechas; es, además, una necesidad, no solo moral, es también una necesidad económica más que nunca" (Castro, 1986, párr. I23).

Como parte de las celebraciones se inauguraron en la provincia obras sociales y económicas, razón por la cual, el 27 de julio de 1986, Fidel visitó el hospital provincial Camilo Cienfuegos y lo dejó inaugurado. También estuvo en la Facultad de Ciencias Médicas, las obras que formaban parte del conjunto hidráulico que triplicó el suministro de agua al acueducto; la Escuela de iniciación deportiva (EIDE) provincial; el antiguo hospital que se restauraba para convertirlo en hospital materno infantil y el puente sobre el río Yayabo, donde saludó y conversó con los vecinos.

Durante los días 5 y 6 de mayo de I989, realizó varios periplos por la provincia, inauguró varias obras y valoró la marcha de otras; en aquella oportunidad asistió al Centro Nacional de Enfermedades de las Abejas, donde felicitó sus trabajadores por el esfuerzo realizado y las posibilidades que tenía el centro para aportar a la salud humana y animal. 
También estuvo en el municipio de Fomento donde pasó por el policlínico, un consultorio médico, el gimnasio fisioterapéutico, la clínica estomatológica y un aula docente profiláctica. Más tarde llegó a la autopista nacional y los puentes elevados. Igualmente arribó a los municipios de Jatibonico y Taguasco, sitios en los que examinó el Combinado de Hormigón Ligero y la Fábrica de Cemento Siguaney, donde se preocupó por la línea de elaboración de cemento blanco. Sus andanzas culminaron en un acto de masas en la Plaza de la Revolución Serafín Sánchez.

Las ideas expuestas por el Comandante en dicho acto estuvieron dirigidas al reconocimiento del avance que había tenido el territorio en ese tiempo, por lo que señaló que lo alcanzado en la fábrica de cemento Siguaney era de "[...] una importancia estratégica para el país..." (Abreu, Aneiros y Fontaine, 20I8, p. 57).

Al concluir su intervención, el líder de la Revolución expuso "Se está trabajando muy serio y ustedes son parte de este esfuerzo, por eso los felicitamos y esperamos que el pueblo de Sancti Spíritus, al igual que nuestra Patria, tenga el futuro que se merece". [...]" (Abreu, Aneiros y Fontaine, 20I8, p. 58).

El 28 de septiembre de I996, Fidel habló a los espirituanos en un acto de masas en la Plaza de la Revolución Serafín Sánchez Valdivia, con motivo del 36 aniversario de los Comités de Defensa de la Revolución (CDR); sus palabras iniciales estuvieron dirigidas a felicitar al pueblo por los logros obtenidos en todas las esferas, resalta sobre todo los logros en el campo de la ciencia y la educación: “[...] Sancti Spíritus no 200 tuvo el 26 pero ha tenido el 28. [...] por su excelente trabajo en este periodo [...]" (Castro, 1996, párr. I).

Con el inicio de la Batalla de Ideas, tras el secuestro del niño Elián González y el reclamo del pueblo cubano para lograr su regreso a Cuba, se iniciaron las tribunas abiertas en toda la Isla y el 25 de mayo del 2002, Sancti Spíritus tuvo el privilegio de realizar la suya, con la presencia de 
Fidel, quien tuvo a su cargo las palabras centrales y dejó bien sentado que la lucha de los cubanos no sería jamás contra el pueblo de Estados Unidos, al tiempo que ratificaba que el cubano era un "[...] pueblo amistoso, solidario y generoso" (Castro, 2002, párr. I). Fue esta su última visita a la provincia espirituana.

\section{El tributo en el regreso a la tierra yayabera}

El 25 de noviembre del 20I6, cuando el general de ejército Raúl Castro, primer secretario del Comité Central del Partido Comunista de Cuba, anunció el fallecimiento del líder de la Revolución, Cuba entera se vistió de luto y Sancti Spíritus se sumó al homenaje, al tributo que se organizó en la Isla. Entre los días 28 y 29 de noviembre de ese año, los espirituanos depositaron una flor ante la imagen del líder en la sede del Comité provincial del Partido Comunista de Cuba y se firmó el juramento de ser fieles seguidores al concepto de Revolución, expresado por el recién fallecido revolucionario.

El I. ${ }^{\circ}$ de diciembre un río de pueblo esperaba para despedir al Comandante eterno, a su paso por toda la provincia las flores y banderas estuvieron presentes, los rostros consternados, su nombre en la frente de los niños y la seguridad en el alma de que ni la muerte lo podría arrancar del corazón de estos hombres, de este pueblo, de esta Revolución.

En el Parque Serafín Sánchez se volvieron a escuchar aquellas palabras del 6 de enero de 1959 que le dieron impulso a la Revolución y que volvieron realidad los sueños. La universidad de la provincia, José Martí Pérez, no estuvo ajena a este tributo y junto a su pueblo participó en todas las actividades organizadas, no solo en aquel momento, sino en todos acontecimientos.

Desde que Fidel regresó a Sancti Spíritus en el propio año 1959 para derrotar la conspiración trujillista, se mantuvo junto a los yayaberos en 
todo el proceso de transformación que ocurría en el territorio y fue fuente de inspiración, a la vez que protagonista, junto al pueblo, de cada uno de los logros que se iban obteniendo.

Hoy, junto a su ejemplo y su recuerdo, atesoramos la guayabera blanca que utilizó en la Cumbre de Cartagena de Indias, Colombia, en junio de I994, y que donó a la Casa de la Guayabera espirituana; así como una serie de fuentes primarias del conocimiento histórico que se han rescatado dentro de las que se destacan las fuentes orales, de algunos protagonistas, que ya no están entre nosotros.

\section{Referencias}

Abreu, C., Aneiros, J.L., y Fontaine, E.J. (2018). Fidel en Sancti Spiritus. Cronología comentada. La Habana: Editora Historia.

Almeida Bosque, J. (2002). La Sierra Maestra y más allá. La Habana: Ediciones Verde Olivo.

Castro Ruz, F. (1959). Discurso pronunciado por el Comandante en jefe Fidel Castro Ruz desde el Balcón de la Sociedad "El Progreso", de Sancti Spíritus, el 6 de enero de $1959 . \quad$ Recuperado de http://www.fidelcastro.cu/es/discursos/discurso-pronunciadodesde-el-balcon-de-la-sociedad-el-progreso-de-sancti-spiritus

Castro Ruz, F. (1966). Discurso pronunciado por el Comandante en Jefe Fidel Castro Ruz en el acto celebrado con los estudiantes de Topes de Collantes, el I8 de julio de I966. Recuperado de http://www.fidelcastro.cu/es/discursos/discurso-pronunciadoen-el-acto-celebrado-con-los-estudiantes-de-topes-de-collantes

Castro Ruz, F. (I97I). Discurso pronunciado por el comandante en Jefe Fidel Castro Ruz en la visita que realizara a la escuela primaria de Meneses, Las Villas, inaugurada el I5 de septiembre de I97I. Recuperado de: http://www.fidelcastro.cu/es/discursos/discurso-pronunciadoen-la-visita-que-realizara-la-escuela-primaria-de-meneses-lasvillas 
Castro Ruz, F. (1986). Discurso pronunciado en el Acto Central Conmemorativo por el XXXIII Aniversario del Asalto al Cuartel Moncada, celebrado en Sancti Spíritus, el 26 de julio de 1986. Recuperado de: http://www.fidelcastro.cu/es/discursos/actocentral-conmemorativo-por-el-xxxiii-aniversario-del-asalto-alcuartel-moncada

Castro Ruz, F. (1996). Discurso pronunciado por Fidel Castro Ruz, presidente de la República de Cuba, en el acto nacional por el 36 aniversario de la constitución de los Comités de Defensa de la Revolución, efectuado en la plaza de la Revolución Mayor General "Serafín Sánchez", de Sancti Spíritus.

Recuperado

de:

http://www.escambray.cu/especiales/fidel/26-septiembre-I996/

Castro Ruz, F. (2002). Discurso pronunciado por el Presidente de la República de Cuba Fidel Castro Ruz, en la Tribuna Abierta de la Revolución, en acto de protesta contra el bloqueo, las calumnias y las amenazas del gobierno de Estados Unidos contra Cuba, en la Plaza Los Olivos, Sancti Spíritus, el 25 de mayo de 2002. Recuperado de: http://www.escambray.cu/especiales/fidel/25-mayo-2002/

Este artículo se publica bajo una licencia de Creative Commons Reconocimiento-NoComercial 4.0 Internacional, y puede ser usados gratuitamente para fines no comerciales, dando los créditos a los autores y a la revista. 